\title{
Avaliação da percepção dos alunos de uma escola do município de Itaporã do Tocantins a respeito da água para as futuras gerações
}

$\mathrm{Na}$ atualidade, uma das maiores preocupações é quanto a escassez da água potável, que está sendo uma realidade cada vez mais próxima da sociedade. A preocupação não se refere a quantidade da água, mas na qualidade. O mundo pode superar esse fato através das futuras gerações que estejam conscientizados sob tais fatores. Desta forma, o presente trabalho tem por objetivo expressar os resultados de uma pesquisa realizada por meio de questionários aplicados aos alunos do Ensino Fundamental II e Médio da Escola Estadual Francisca Alves de Alencar, localizada no Município de Itaporã do Tocantins, sobre a concepção e o conhecimento dos alunos a respeito da água que é um bem finito e que poderá estar ausente nas futuras gerações. A escassez dos recursos hídricos é um tema que se agrava continuamente no decorrer do tempo, e vem sendo apresentado volumes cada vez mais baixo no reservatório local. Realizaram-se coletas de dados, através de entrevista por meio de questionário e observação direta através dela buscou-se compreender as opiniões e sugestões de cada educando para os problemas levantados em relação ao tema abordado. O estudo realizado comprova a necessidade de novos hábitos de conservação da água, sendo uma das alternativas a água de reuso, uma forma de reaproveitar e reduzir o consumo excessivo. $O$ artigo contribuirá para o âmbito acadêmico através de estudos realizados que poderá ser utilizada a fim de identificar e desenvolver novos métodos sustentáveis, uma consciência que deverá ser tomada, pois é uma questão de sobrevivência e uma forma de garantir que as novas gerações usufruam desse bem tão precioso para a humanidade.

Palavras-chave: Meio Ambiente; Conservação; Conscientização; Consumo Excessivo.

\section{Evaluation of the perception of the students of a school in the city of Itaporã do Tocantins about water for future generations}

One of the biggest concerns today is the scarcity of drinking water, which is becoming an ever closer reality of society. Concern is not about water quantity but quality. The world can overcome this fact through future generations who are aware of such factors. Thus, this paper aims to express the results of a survey conducted through questionnaires applied to students of Elementary School II and High School Francisca Alves de Alencar, located in the municipality of Itapora do Tocantins, about the design and students' knowledge of water that is a finite good that may be absent in future generations. The scarcity of water resources is a theme that continually worsens over time, and increasingly low volumes have been presented in the local reservoir. Data were collected through interviews through questionnaires and direct observation through it. We sought to understand the opinions and suggestions of each student for the problems raised in relation to the topic addressed. The study proves the need for new habits of water conservation, being one of the alternatives to reuse water, a way to reuse and reduce excessive consumption. The article will contribute to the academic field through studies that can be used to identify and develop new sustainable methods, an awareness that must be taken, as it is a matter of survival and a way to ensure that new generations enjoy this good. so precious to humanity

Keywords: Environment; Conservation; Awareness; Excessive consumption.

Topic: Desenvolvimento, Sustentabilidade e Meio Ambiente

Reviewed anonymously in the process of blind peer.
Received: 19/07/2019

Approved: 29/10/2019
Sandra Alencar de Sousa Mendes

Instituto Educacional Santa Catarina, Brasil

http://lattes.cnpq.br/0730561205498572

sandraalencar123@hotmail.com

Kairo Sousa Mendes

Instituto Educacional Santa Catarina, Brasil

http://lattes.cnpq.br/1750716941120718

kairosm@hotmail.com

Laisy Giordana Lopes Carvalho

Instituto Educacional Santa Catarina, Brasi

http://lattes.cnpq.br/2733965769712173

laisygiordanal9@gmail.com

\author{
Marcela Coelho (iD) \\ Instituto Educacional Santa Catarina, Brasil \\ http://lattes.cnpq.br/2803075967598184 \\ http://orcid.org/0000-0001-8081-7413 \\ marcela.coelho2015@hotmail.com \\ Ana Paula Martins Guimarães \\ Universidade Federal do Tocantins, Brasi \\ http://lattes.cnpq.br/5309168123830683 \\ http://orcid.org/0000-0002-0926-7962 \\ biologa.apmg@gmail.com
}

Referencing this:

MENDES, S. A. S.; MENDES, K. S.; CARVALHO, L. G. L.; COELHO, M.; GUIMARÃES, A. P. M.. Avaliação da percepção dos alunos de uma escola do município de Itaporã do Tocantins a respeito da água para as futuras gerações. Natural Resources, v.9, n.3, p.18-32, 2019. DOI: http://doi.org/10.6008/CBPC2237-9290.2019.003.0003 


\section{INTRODUÇÃO}

A água é um recurso natural de suma importância para à vida na Terra, sendo considerada a molécula fundamental no metabolismo de todas as células vivas do planeta, além de estar fortemente envolvida nas diversas formas de uso do ser humano (SILVEIRA et al., 2017). Apesar de ser um bem público, vem se tornando pouco a pouco um recurso escasso que requer rigoroso cuidado (SELBORNE, 2002; LEVY NETO, 2006; ROBERTO et al., 2017), no intuito de conservar este bem para as próximas gerações.

Roberto et al. (2017), afirmam que, um dos motivos que pode estar levando a escassez da água no Planeta são as fortes ações antrópicas. Para que a água seja entendida pela maioria da população global de que se trata de um bem finito, é necessário trabalhar a importância deste bem para a vida no planeta principalmente dentro do ambiente escolar, sendo discutido enfaticamente no decorrer de todas as etapas do desenvolvimento do indivíduo, viabilizando uma conexão conservadora e defensora deste bem para o futuro da humanidade.

Por se tratar de um bem tão importante e que vem sofrendo fortes impactos mediados pela ação antrópica, nos últimos anos não somente a água, mas também todas as questões ambientais passaram a ser tratadas pelos Parâmetros Curriculares Nacionais (PCNs) como Temas a serem trabalhados ostensivamente por todas as disciplinas envolvidas no currículo do ensino Fundamental e Médio das Escolas do território brasileiro (CHAUI, 2016). Por se tratar de ações que podem amenizar situações recorrentes e urgentes no Brasil, estes temas então, foram denominados como 'Temas Transversais', que transpassam todas as disciplinas do currículo escolar em todas as etapas de formação do aluno.

Apesar de não se tratar de disciplinas, mas sim, temas a serem trabalhados transversalmente aos conteúdos obrigatórios da maioria das disciplinas do currículo, estes, estão em comum acordo com os conteúdos, abrangendo inúmeras áreas de forma generalizada e estão unidos ao conhecimento a ser alcançado através da prática pedagógica, com o intuito de levar a reflexão sobre determinadas ações exercidas pelos discentes ou protagonistas envolvidos no processo corriqueiramente (VIVEIRO, 2006). Envolvem essencialmente métodos e ações a serem praticadas, mas que a eficiência desta metodologia aderida só poderá ser analisada em longo prazo (OLIVEIRA, 2007).

Portanto, entende-se que educação ambiental como um Tema Transversal é essencial nas escolas públicas e que precisa de uma atenção especial, a fim de implantar nos alunos costumes e hábitos que favoreçam o relacionamento destes, com o meio natural de forma respeitosa e racional, levando-os a compreender a importância de mudar os seus hábitos com relação ao ambiente no qual vivem, estabelecendo diferentes rotinas e noções de conservação e preservação, com um novo olhar para estas questões (CARVALHO, 2006; SANTOS, 2007) a fim de que, estes conhecimentos sejam repassados pelos protagonistas da educação aos indivíduos comuns ao seu círculo social, estimulando-os a serem praticantes do desenvolvimento sustentável natural e comunitário (LIMA, 2004).

A afinidade dentre o meio ambiente e o ensino para o direito e deveres do cidadão, é de atribuir uma função cada vez mais desafiante e exigindo a manifestação de novos conhecimentos a alcançar de maneira 
geral, que dificultem as ameaças ambientais que se alargam (JACOBI, 2003). Desta forma, o presente trabalho tem por objetivo expressar os resultados de uma pesquisa realizada por meio de questionário aplicado aos alunos do Ensino Fundamental II e Médio da Escola Estadual Francisca Alves de Alencar, localizada no Município de Itaporã do Tocantins, sobre a concepção e o conhecimento dos alunos a respeito da água que é um bem finito e que poderá estar ausente nas futuras gerações.

\section{MATERIAIS E MÉTODOS}

\section{Áreas de Coleta de dados}

Na literatura, múltiplos estudos mostram para atitudes de caráter consequente e conservação da água. Faz-se necessário ter em presença que muitas implicações recusam que serão enfatizadas ao longo do estudo que poderão ser diminuídas se acontecerem transformações de comportamento e se a comunidade optar a seguir novos métodos mais ativos, possível de economizar água nos setores mais afetados à sua oferta, porém não somente neles, pois a água é afinal, a matriz da vida no mundo. Assim é fundamental iniciativa de todos, e um mundo com atitudes inteligentes podem estar ao alcance se forem realizadas ações imediatas e seguidos parâmetros (ESTENDER, 2015).

Nesse ensejo foi realizada uma pesquisa no Colégio Estadual Francisca Alves de Alencar (CEFAA), localizado no Município de Itaporã do Tocantins. Este Município se encontra a uma distância aproximada de 270 km da Capital do Estado, Palmas do Tocantins e, a 1.191 km da Capital Brasileira, Brasil. O Município de Itaporã do Tocantins está localizado na Mesorregião Ocidental do Tocantins e na Microrregião de Miracema do Tocantins, bacia do Araguaia, na Amazônia Legal Tocantinense, com coordenadas geográficas aproximadas de $8^{\circ} 34^{\prime} 17^{\prime \prime} \mathrm{S}$ e $48^{\circ} 41^{\prime} 21^{\prime \prime} \mathrm{W}$, com altitude de 350 metros a cima do nível do mar (Figura 1).

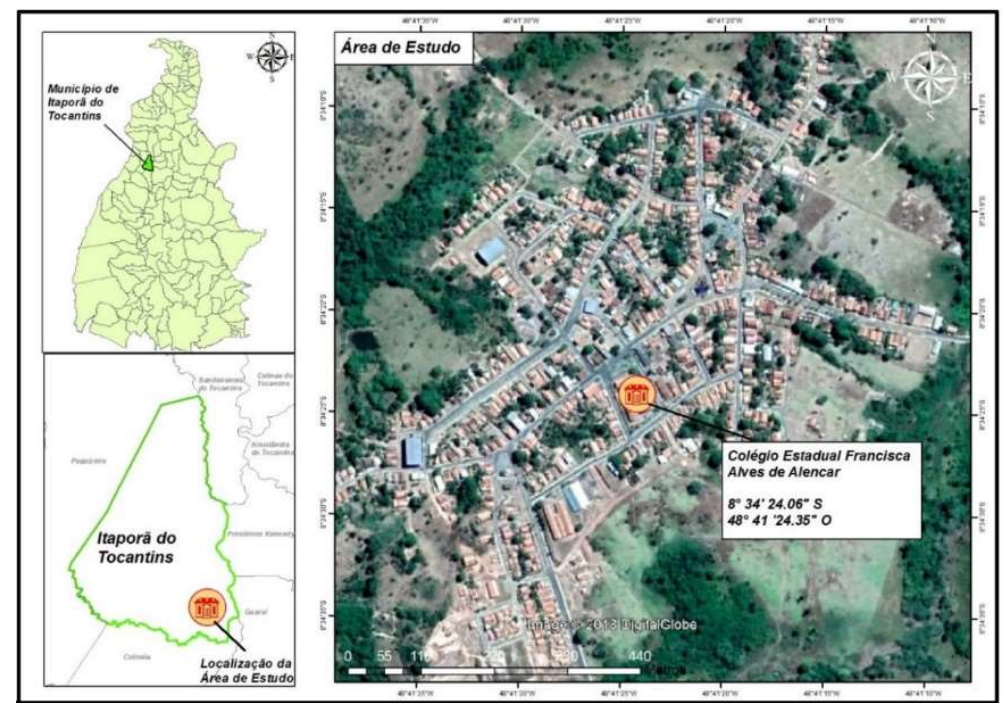

Figura 1: Mapa do Estado do Tocantins com destaque para o Município de Itaporã e do Colégio Estadual Francisca Alves de Alencar, onde ocorreu a presente pesquisa.

Itaporã tem uma população estimada em 2017 de 2.465 pessoas e densidade populacional de 2,5 habitantes por $\mathrm{Km}^{2}$ (IBGE, 2016). Os aspectos culturais atrativos do Município de Itaporã são as festas populares, como aniversário da cidade, festejos religiosos e festas juninas, já os aspectos econômicos da 
cidade são marcados até 2010 pela agropecuária com uma margem de 55,6\% na agricultura, 37,4\% na indústria e 7\% para a criação de bovinos (ACSELRAD, 2008).

O Município está sob o domínio do Cerrado e apresenta alguns fragmentos de flores denominados épocas. O solo é caracterizado como humoso a argiloso, os principais córregos no município é a barreira, barreiro, Córrego Santo Euzébio, Cachoeira na Chácara Três Corações, mato de banana, grota rica, e o córrego peba. O clima é tropical, marcado por um período de seca e outro chuvoso (SEPLAN, 2012). De acordo com a escala de Köppen e Geiger, este clima é classificado como do tipo aw, com temperatura média anual de $25.6^{\circ} \mathrm{C}$, e nível pluviométrico de $1969 \mathrm{~mm}$ no ano (KÖPPEN, 1931).

\section{Características do questionário e coleta de dados}

A coleta de dados foi realizada por meio de um questionário elaborado seguindo as recomendações de Gil (1998) e Lakatos et al. (1999), contendo perguntas de múltipla escolha, com respostas fechadas e uma única alternativa correta na maioria das perguntas, para avaliar o conhecimento e a concepção destes discentes, matriculados no ensino fundamental II e ensino médio de Colégio Estadual em 2018, sobre a importância da conservação da água, os desafios voltados a sua escassez e a ações necessárias para a conservação e preservação deste recurso para as futuras gerações do Município de Itaporã do Tocantins. Este mesmo método de pesquisa por questionários aplicados na área da educação, também foi utilizado por Ramos et al. (2017), Barros et al. (2017) e Maciel et al. (2017).

O questionário aplicado para os discentes matriculados no Colégio continha 10 questões, na qual o cabeçalho do mesmo abordava perguntas referente a data da aplicação do questionário, sexo, série, turma e turno. Por se tratar de um assunto tão importante na vida dos seres vivos, o questionário esclareceu da melhor forma as perguntas elaboradas, onde teve uma quantidade de 5 perguntas, formando um rico conhecimento de dados.

Antes da aplicação do questionário na Unidade Escolar (U.E.) foi apresentado o termo de livre esclarecimento e consentimento a Gestora da U.E.. Este termo, explica de acordo com a lei 196/96 a finalidade do trabalho, assim como, a apresentação do modelo que seria aplicado nas turmas daquele Colégio, a fim de conseguir a permissão para a realização da pesquisa e a publicação dos resultados encontrados, para que, estes resultados possam contribuir para conscientização da importância da utilização dos Temas Transversais como eixo norteador na educação básica com relação as problemáticas emergentes no Brasil voltadas aos recursos naturais e a forma como são explorados e utilizados, assim como, sensibilizar os alunos com relação aos assuntos de urgência e abrangência nacional, principalmente, aqueles que apresentam íntima relação com a educação ambiental, enfatizando a importância da água para a vida na Terra.

No geral, o questionário foi aplicado em 12 turmas do Colégio, sendo que, 8 delas faziam parte do

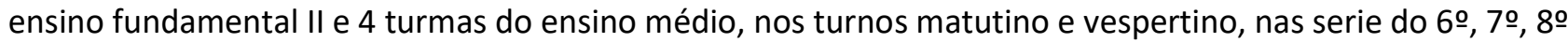
e 9o, (Ensino Fundamental); e 1으, 20 e 3으 (Ensino Médio). O tempo utilizado para a resolução dos questionários por turma foi entre 40 a 45 minutos, equivalente a uma aula da grade curricular convencional 
da rede Estadual de Ensino ao qual o Colégio se integra.

\section{Tabulações e expressão dos resultados}

Os resultados obtidos por meio da aplicação do questionário foram tabulados em tabelas do programa Microsoft Excel, utilizando-se de estatística descritiva de acordo com Reis (2000), para a expressão dos resultados por meio de tabelas e gráficos, descrevendo e discutindo os resultados expressos, comparando os resultados obtidos dentro da mesma turma e entre todas as turmas trabalhadas na escola.

\section{RESULTADOS E DISCUSSÃO}

O CEFAA possui em geral 295 alunos matriculados nos dois turnos de funcionamento, e destes alunos, somente 247 responderam ao questionário, obtendo a porcentagem de $(83,73 \%)$, na qual 48 alunos estavam ausentes na data de sua aplicação, chegando a uma porcentagem de $(16,27 \%)$ dos alunos que faltaram. Dentre os estudantes que responderam ao questionário, 113 eram do sexo feminino, e 134 do sexo masculino.

Tabela 1: Tabela que expressa à quantidade alunos matriculados por turma e a porcentagem de alunos que resolveram o questionário no CEFAA.

\begin{tabular}{|c|c|c|c|c|}
\hline \multirow{2}{*}{$\begin{array}{l}\text { Turno } \\
\text { Série }\end{array}$} & \multicolumn{2}{|c|}{ MATUTINO } & \multicolumn{2}{|c|}{ VESPERTINO } \\
\hline & Mat. & \% Pre. & Mat. & \% Pre. \\
\hline 60 Ano & 26 & $92,31 \%$ & 24 & $95,8 \%$ \\
\hline 70 Ano & 26 & $96,15 \%$ & 28 & $85,7 \%$ \\
\hline $8^{\circ}$ Ano & 16 & $81,25 \%$ & 25 & $80 \%$ \\
\hline $9^{\circ}$ Ano & 19 & $94,74 \%$ & 25 & $84 \%$ \\
\hline 1a Série & $*$ & $*$ & 40 & $75 \%$ \\
\hline 2a Série & 15 & $93,4 \%$ & 22 & $77,3 \%$ \\
\hline 3a Série & $*$ & $*$ & 29 & $62,1 \%$ \\
\hline \multicolumn{4}{|c|}{ Total de alunos matriculados } & 295 \\
\hline \multicolumn{4}{|c|}{ Total de alunos presentes } & 247 \\
\hline
\end{tabular}

Mat.= Matriculados; Pre. = Presentes; $(*)$ séries que não formaram turma no ano de 2018.

Os alunos matriculados no CEFAA, dos que estavam presentes para responderem o questionário que foi aplicado no Ensino Fundamental II e Ensino Médio, no turno matutino, dos 26 alunos matriculados no 6o ano matutino, $92,31 \%$ responderam o questionário; no $7^{\circ}$ ano matutino dos 26 alunos matriculados, 96,25\% responderam o questionário; dos 16 alunos matriculados no 8o ano matutino 81,25\% responderam o questionário; dos 19 alunos matriculados no 9o ano matutino 94,74\% responderam o questionário. Já na 2ạ série matutina dos 15 alunos matriculados $93,4 \%$ responderam o questionário.

Já no Ensino Fundamental Il e Ensino Médio, no turno vespertino, dos alunos matriculados no 60 ano vespertino somente $95,8 \%$ responderam o questionário; no 70 ano vespertino $85,7 \%$, no 8 o ano vespertino $80 \%$, no 9o ano vespertino $84 \%$. Já na1a série vespertina, dos 40 alunos matriculados, somente $75 \%$ responderam o questionário; na 2 a série vespertina $77,3 \%$ e na 3 a série vespertina somente $62,1 \%$ responderam o questionário aplicado nesta turma.

Quanto à primeira pergunta do questionário que diz respeito ‘a água potável ser um bem infinito no Planeta Terra' (Figura 2). Percebe-se que a maioria dos alunos contém informações suficientes para compreender que a água do planeta não se trata de um bem infinito, deixando está observação clara na 
resolução do questionário, sendo que, somente algumas turmas do Colégio tinham uma noção de que se não houver um cuidado especial com relação à água que poderá faltar para as próximas gerações.

As turmas do Ensino Fundamental II e Ensino Médio do período matutino obtiveram os seguintes resultados: no 60 ano 75\% afirmam que a água é um bem infinito e somente 16,7\% disseram que não; do 7응 ano $36 \%$ dos alunos afirmaram que sim e a maioria (56\%) afirmaram que não. Já no 8o ano $85 \%$ acreditam que sim e o restante não. No 9 ㅇ ano $77,8 \%$ dizem que a água não é um bem infinito e os outros acreditam que sim ou não sabem e na 2 a série, a maioria $(78,6 \%)$ afirmam que não o restante que sim ou não sabem.

Quanto às turmas do período vespertino, obtiveram-se os seguintes resultados: no 60 ano $95,7 \%$ acreditam que a água é um bem infinito. Já no 70 ano maioria disseram $(54,2 \%)$ que não e o restante não sabe ou acreditam que sim a água é infinita. O 8o ano 35\% disse que sim, 50\% não e 15\% não sabem. No 9o ano vespertino $52,4 \%$ acreditam que sim e $42,8 \%$ não e o restante não sabe. Já na 1ạ série a maioria (46,6\%) dos alunos não sabem responder e somente $36,7 \%$ acreditam que não, $16,7 \%$ sim e na 2a série $100 \%$ dos alunos afirmaram que não, enquanto que na 3ạ série a maioria $(61,1 \%)$ respondeu não, $22,2 \%$ não sabem e o restante acredita que a água é um bem infinito.

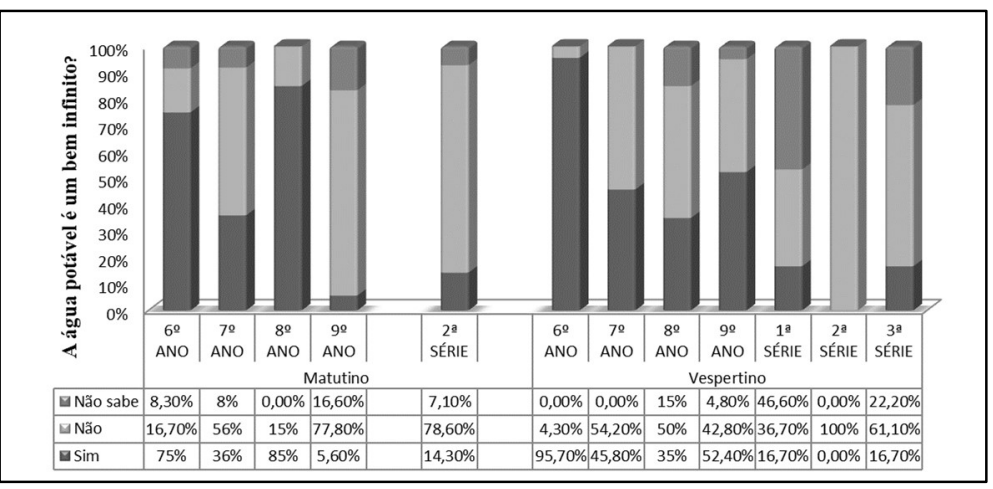

Figura 2: Respostas da primeira pergunta do questionário sobre a concepção dos alunos a respeito da durabilidade da água no planeta.

Com os resultados expressos a cima, mesmo alguns alunos de algumas turmas demonstrarem saber que a água se trata de um bem finito, ainda assim, um número alto afirma que é um bem infinito, o que é preocupante, pois os resultados podem refletir o pensamento de alguns representantes da população de Itaporã.

De acordo com afirmações realizadas por Dalzotto et al. (2009), demostra para que se tenha entendimento assim como decorrência disto, a conscientização dos estudantes em semelhança aos recursos de água de sua sociedade é de grande interesse que a educação ambiental façam práticas que atraiam os discentes em condições de preparação mútua pondo os mesmos em uma situação em que a compressão esteja estabelecida com apoio de conhecimento da existência, causando assim com que esses pequeninos indivíduos da comunidade sejam capazes de passar as informações para a sociedade a seu redor. Conforme Silva et al. (2014), diz também que o cuidado ambiental que os discentes aprendem no âmbito escolar, é de fundamental solução para reduzir, ou ainda acabar, com os efeitos ocasionados pela deficiência de entendimento da comunidade.

A figura 3 do presente trabalho faz uma relação entre as turmas que responderam que a água se 
trata de um bem finito e é perceptível que a maioria das turmas tem um pensamento inverso a respeito deste tema, sendo que, somente as turmas do 9 o ano e da 2a série matutinos acreditam que a água não é um bem infinito. Quanto às turmas do período vespertino somente a 2a série está de acordo com o esperado para a resposta, em que $100 \%$ dos alunos acreditam que não se trata de um bem infinito. A 3 a série também apresentou resultado satisfatório com relação a esta questão, pois a maioria deu a entender que sabem que a água é um bem finito.

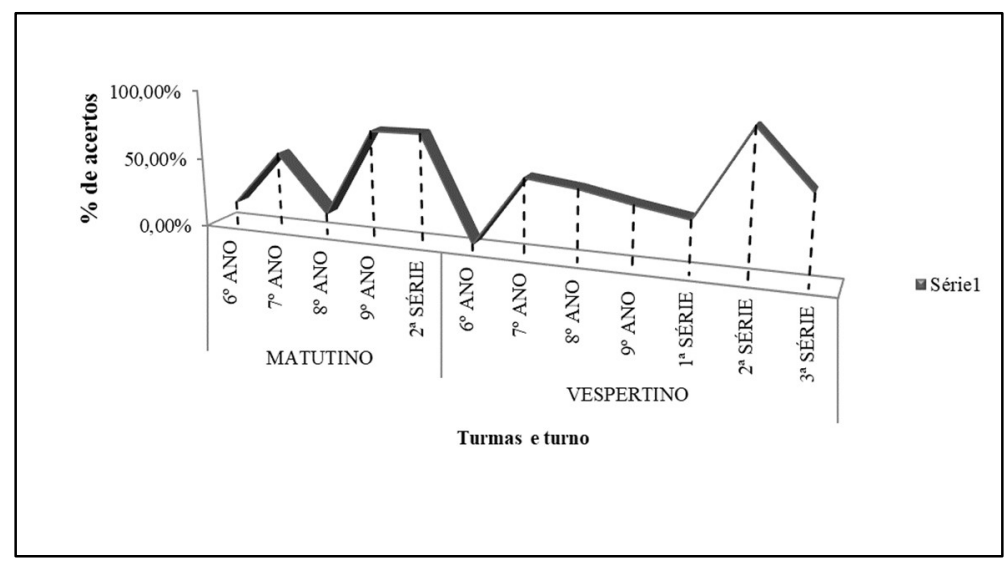

Figura 3: Gráfico de comparação entre as turmas que responderam não à questão no 1 do questionário.

Com relação pergunta de número 2 do questionário (Figura 4) 'Na sua concepção, o que é preciso para que uma água seja considerada potável?', as respostas nas turmas do período matutino apresentaram os seguintes resultados: № 60 ano somente $58,3 \%$ afirmaram que a água para ser potável deve estar livre de agentes causadores de doenças e o restante que deve ser inodora, ou incolor, não conter gosto à temperatura ambiente. Já nas turmas de 7으, 8 e 9ㅇa ano os resultados $60 \%, 61,5 \%$ e $61,1 \%$ respectivamente acreditam que a água para ser potável deve estar livre de agentes patogênicos e o restante acredita que deve estar incolor, inodora, sem gosto e a temperatura ambiente. Já os alunos da 2a série matutina 100\% afirmaram deve estar livre de agentes causadores de doenças.

De acordo com os resultados a cima, percebe-se que a maioria dos alunos do período matutino possui uma forte concepção de que para água estar apta ao consumo humano é necessário estar livre de agentes causadores de doenças. Estes resultados estão de acordo com afirmações realizadas por Darolt (2008), diz que a ausência de tratamento correto quanto à quantidade de dejetos dos indivíduos produzidos é exatamente um dos maiores problemas para o ambiente e a comunidade. Desta forma com o processo de tratamento de esgoto humano é essencial nas civilizações urbanas, da mesma maneira precisa também obter maior atenção na zona rural, em função do aumento e ser um potencial poluidor de agentes causadores de doenças como, vírus, bactérias, fungos e parasitas.

De acordo com Silva et al. (2018), a água não tratada é um dos principais veículos de disseminação de doenças por possuir alta taxa de contaminação por microrganismos sendo um dos responsáveis por determinar os riscos à saúde coletiva de uma certa população. Segundo Roberto et al. (2017), Rodrigues et al. (2017), para evitar a disseminação de doenças veiculadas pela água é necessário submetê-la a testes fiscos, químicos e microbiológicos, assim como, seguir os critérios de saneamento básico atribuídos a 
qualidade da água a fim de comprovar a sua viabilidade para o consumo humano.

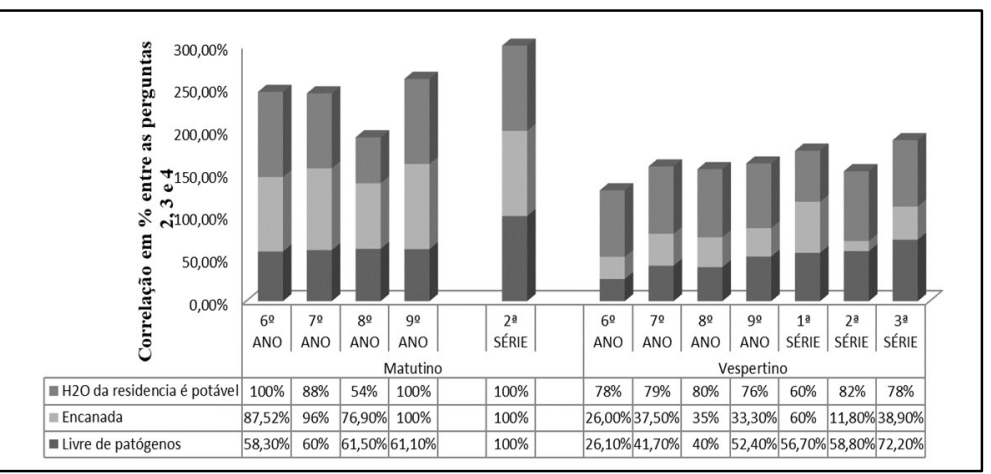

Figura 4. Representação das respostas encontradas nas questões 2, 3 e 4 que faz relação entre a fonte de água consumida em sua residência com a potencialidade ou não desta fonte causar doenças a fim de reafirmar as questões anteriores.

A mesma pergunta foi feita as turmas do período vespertino, e os resultados encontrados foram os seguintes: nas turmas de Ensino Fundamental (6으, 7으, 8o e 9o ano), 26,1\%, 41,7\%, 40\%, 52,4\% afirmaram respectivamente que para a água ser considerada portável, a mesma deve estar livre de agentes causadores de doenças e os outros alunos marcaram que deve ser inodora, incolor, sem gosto e a temperatura ambiente e 1 único aluno do 9o ano que afirmou que todas as alternativas estariam corretas. Alguns alunos do 6 ano não marcaram nenhuma alternativa. Já os alunos da 1aㅡ, 2aㅡ e 3ํㅗ séries, 56,7\%, 58,8\% e 72,2\% afirmaram que deve estar livre de doenças, e o restante dos alunos marcaram as alternativas incorretas para esta questão.

Com estes resultados, é possível mais uma vez perceber que as turmas do período vespertino apresentam conhecimento a respeito do tema abordado no presente trabalho, sendo possível então dar ênfase para as turmas da 2aㅡ e da $3 \stackrel{a}{a}$ série vespertinas. Em referência as questões 3 e 4 do questionário (Figura 3) ('a água que é utilizada em sua residência vem de qual fonte?' e 'na sua concepção, a água utilizada na sua residência é potável?'). As respostas destas perguntas para as turmas do período matutino são: os alunos do 60 ano $100 \%$ afirmam que a água da sua residência é potável, porém, somente $87,52 \%$ disseram que a água utilizada em sua residência é encanada, deixando assim, uma dúvida com relação as respostas dos alunos e o seu conhecimento a respeito do que seria uma água potável ou não.

Já os alunos das turmas do 7ำ, 8ํ e $9^{\circ}$ anos $88 \%, 54 \%$ e $100 \%$ simultaneamente afirmam que a água de suas residências é potável, que em comparação com a questão número 3 que pergunta qual é a fonte desta água 96\%, 76,90\% e 100\% respectivamente afirmam que a água de suas residências é encanada. Para as turmas do Ensino Médio do mesmo período, em que na 2ª série, 100\% dos alunos afirmam que a água de sua residência é potável, pois é encanada, estando de acordo com conhecimento em que estes alunos apresentam sobre a água para ser potável deve estar livre de patógenos.

Nestas questões é possível observar que a maioria dos alunos faz uma relação entre a água de suas residências serem potável e a fonte de abastecimento, assim como, faz um link de conhecimento com a questão número 2 do questionário, onde a maioria dos alunos do Ensino Fundamental e Médio, especialmente a turma da 2a série, que afirma que a água potável deve estar livre de agentes causadores de doenças, obtendo assim, resultados de acordo com o esperado. 
Estas mesmas questões foram aplicadas nas turmas do período vespertino em que apresentaram os seguintes resultados: No 60 ano $78 \%$ dos alunos disseram que a água de suas casas é potável, porém, somente $26 \%$ afirmaram se tratar de uma água encanada. Enquanto que as turmas do 7ㅇ, 8 e 9o ano 79\%, 80\% e $76 \%$ afirmaram concomitantemente que a água utilizada em suas residências é potável, porém, somente $37,5 \%$, 35\% e 33\% disseram que está água julgada potável é encanada, enquanto que os outros alunos, disseram que a fonte oriunda da água que bebe é de córregos, rios, poções e outros.

Já os resultados obtidos para as mesmas questões discutidas no parágrafo anterior com as turmas

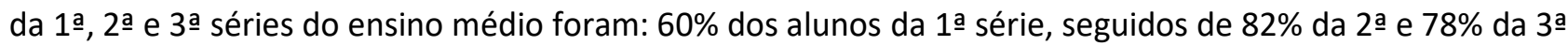
série afirmam que a água que é consumida em suas residências é potável, porém, $60 \%, 11 \%$ e $38,9 \%$ consomem água encanada. As respostas de ambas as perguntas expressas por estes alunos, pois como podem afirmar que a água que bebem em suas residências é potável se uma média de $63,4 \%$ dos alunos afirmou que a água pela qual consomem é oriunda de córregos, rios e poços.

A tabela 2 do presente trabalho mostra os resultados encontrados nas perguntas 5 e 6 do questionário. Com relação a questão 5, o questionário pergunta aos alunos se alguma vez já receberam orientações por parte dos profissionais do Colégio a respeito das formas e da importância de se conservar a água para o futuro e em quais disciplinas obtiveram estas informações. Nas turmas de Ensino Fundamental matutina obtiveram-se os seguintes resultados: No 60 ano $92 \%$ dos alunos disseram que já receberam informações a respeito da importância de conservar a água e afirmaram ainda que a disciplina os professores da disciplina de ciências e geografia concomitantemente com $79,1 \%$ das afirmações, seguido do professor de português com $12,5 \%$, sendo que as outras disciplinas apresentaram somente $8,4 \%$ das afirmações e estes mesmos alunos alegam ainda que, existem disciplinas em os professores nunca tocaram no assunto 'água'.

Com relação a água potável ser adequada ao consumo humano, sem oferecer perigo a saúde, a mesma precisa ser tratada, limpa e não conter agentes causadores de doenças (IBGE, 2000). De acordo com Ricci (2001), que afirma com informações da UNICEF, que $24 \%$ da população convive sem água encanada e $30 \%$ sem esgoto.

Já nas turmas de 7오 8ㅇ e 9 ano matutino, 96\%, 77\% e $100 \%$ dos alunos simultaneamente afirmaram que já tiveram orientações por funcionário do Colégio sobre a importância de conservação da água e afirmaram ainda que, em média $81 \%$ destas informações foram repassadas pelo professor da disciplina de ciências, seguidas de 19\% da disciplina de geografia, sendo que, as outras disciplinas não trabalham o tema. Nas turmas de ensino médio do período matutino no que diz respeito a 2a série $100 \%$ dos alunos afirmam que o Colégio trabalha o tema 'água e a importância de sua conservação'. Estes alunos afirmaram ainda que, as disciplinas que mais trabalham com esta temática são: geografia, química e biologia simultaneamente.

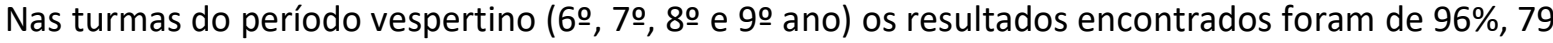
\%, 90 \% e 76 \% simultaneamente afirmaram que o Colégio trabalha a importância da conservação da água e que as disciplinas que mais trabalham este tema são biologia, geografia, história, física e em alguns casos na disciplina de Ensino Religioso e Português, sendo que, as outras disciplinas nunca trabalharam a temática aqui descrita. Já para as turmas do ensino médio (10, 2ํ e 3올ie), 83\%, 100\% e 83\% afirmaram que o Colégio 
trabalha o tema e que as disciplinas carro chefe nesta discussão são: biologia, geografia, química, história, física, redação, educação física e ensino religioso. Estes alunos afirmam ainda que, algumas disciplinas nunca trabalharam a temática neste Colégio.

Tabela 2: Respostas em porcentagens das questões 5 e 6 do questionário que diz respeito a atuação da escola no processo de ensino aprendizagem do Temas Transversal 'Educação e Ambiente'.

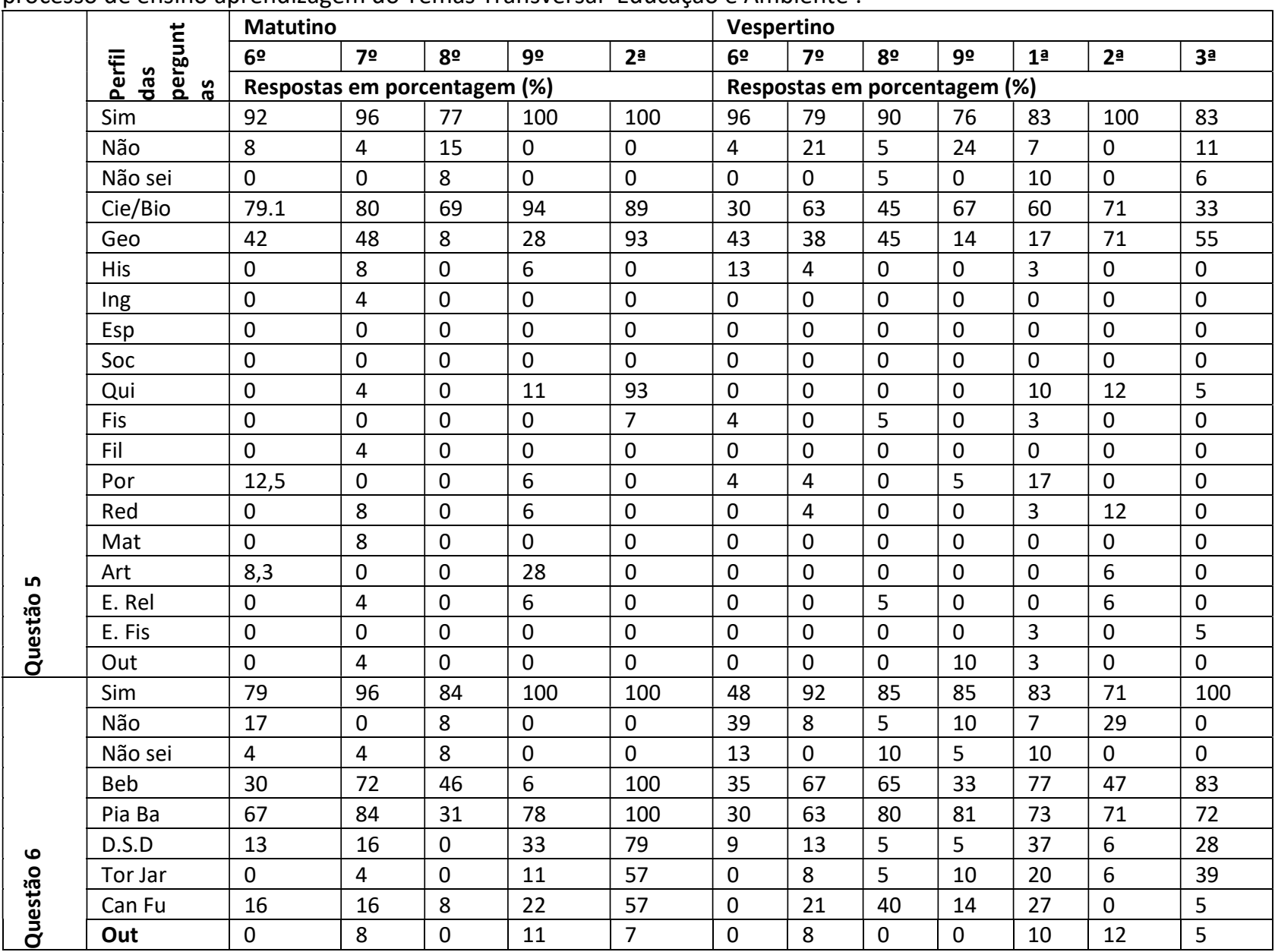

(5) $\mathrm{Cie} /$ Bio = Ciências/Biologia; Geo = Geografia; His = História; Ing = Inglês; Esp = Espanhol; Soc = Sociologia; Qui = Química; Fis = Física; Fil = Filosofia; Por = Português; Red = Redação; Mat = Matemática; Art = Artes; E. Rel = Ensino Religioso; E. Fis = Educação Física e Out = Outros (6) Beb = Bebedouro; Pia Ba = Pia do banheiro; D.S.D = Descarga do sanitário com defeito; Tor Jar = Torneiras do jardim; Can Fu = Canos furados e Out = Outros.

A pergunta número 6 do questionário aplicado no Colégio Francisca Alves de Alencar, interroga os alunos se nas dependências da Unidade Escolar ocorre desperdício de água e se ocorre, em quais locais do Colégio. As turmas do período matutino apresentaram o seguinte perfil: nas turmas do ensino fundamental (6으, 7으, 8 e 9o) afirmaram que, 79\%, 96\%, 84\% e 100\% respectivamente disseram que existe desperdício de água no Colégio e em várias localidades. As turmas de 6으 ao 8ㅇ afirmaram que o local do Colégio em que ocorre o maior desperdício de água é no bebedouro, enquanto que o 9o ano afirma que o desperdício ocorre principalmente na pia do banheiro, porém, alguns alunos de todas as turmas detectaram que também ocorre desperdício na descarga dos sanitários com defeito, nos canos furados e também nas torneiras que molham o jardim e em outros locais do Colégio.

Esta pergunta também foi feita aos alunos do ensino médio (2 ${ }^{a}$ série) do período matutino, e os resultados foram os seguintes: $100 \%$ dos alunos disseram que ocorre desperdício de água no Colégio e que este desperdício ocorre predominantemente no bebedouro, na pia do banheiro e nas descargas danificadas, 
mas ocorre também em todas as outras localidades da escola.

Já para as turmas do período vespertino a questão número 6 obteve o seguinte resultado: as turmas do ensino fundamental (6으, 7으, 8ㅇ e 9o ano), $92 \%, 85 \%$ (7으 e 8 o ano) $85 \%$ respectivamente disseram que existe sim desperdício de água no Colégio e que os locais de maior frequência são: o bebedouro e as pias do banheiro são os maiores responsáveis pelo desperdício, mas que, também ocorrem desperdícios em outras localidades do Colégio. No ensino médio (1a , 2aㅡ e 3ạ série), 83\%, 71\% e 100\% afirmaram que realmente ocorre o desperdício deste recurso natural no Colégio, e assim como no Ensino Fundamental, estes alunos dizem que os locais de maior frequência no Colégio é o bebedouro e as pias do banheiro, ocorrendo também fuga de água em outras localidades do Colégio.

Com relação às perguntas 7 e 8, o questionário faz uma comparação entre o hábito de fechar a torneira e as práticas de reutilização da água (Figura 5). Quando são comparados os hábitos com relação a conservação da água é possível que as respostas dos alunos se auto afirmem com uma contra resposta, sendo que as turmas do período matutino obtiveram os seguintes resultados: no 6o ano somente $8 \%$ dos alunos fecham a torneira ao escovar os dentes, já para as turmas do 7으, 8 e 9o ano, 100\%, 85\% e 89\% afirmam respectivamente que tem o hábito de fechar a torneira ao escovar os dentes. Conforme Victorino (2007), a deficiência de água potável atual não aconteça por motivo da natureza, e sim por falta da utilização adequada, que constitui no desperdício e descuido, causados por práticas degradadas da lógica do uso racional da água potável.

Para reafirmar o hábito de economia de água foi elaborada uma pergunta sobre a reutilização ou não da água, e se é reutilizada, em qual prática doméstica?. Os mesmos alunos citados a cima do Ensino Fundamental matutino $87,5 \%, 88 \%, 69 \%$ e $78 \%$ afirmam respectivamente que em suas residências é praticado o hábito de reutilização da água, sendo que, de forma unânime os alunos declaram que a maior prática em que é reutilizada água em suas residências é para lavar a casa e as calçadas. Porém, também reutilizam a água para molhar plantas ou hortas, lavar roupa, veículos, molhar o quintal e outros.

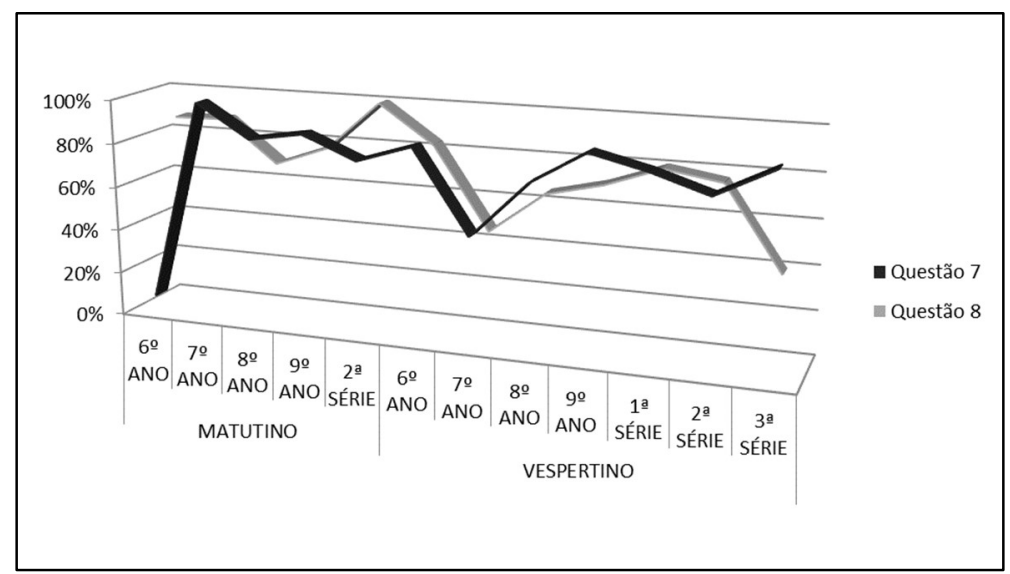

Figura 5: Análise comparativa entre a questão 7 que pergunta ao aluno se o mesmo tem o hábito de fechar a torneira ao escovar os dentes e com a 8 que faz referência a reutilização ou não da água.

Em um trabalho realizado por Lima et al. (2018), intitulado "Analfabetismo ambiental: a percepção dos docentes e discentes sobre o ambiente de uma escola do município de Guaraí/TO", onde, foi aplicado 
um questionário a alunos e professores de uma escola de Guaraí a fim de conhecer a sua concepção sobre ambiente. Neste questionário, a maioria dos alunos e dos professores responderam que, uma das ações necessárias a serem tomadas a fim de conservar o ambiente seria diminuir o consumo da água, demonstrando então que, estes indivíduos já conhecem as causas e as consequências para as futuras gerações caso o ciclo da água venha a ser prejudicado no planeta.

A única turma de ensino médio do período matutino (2a série) $79 \%$ afirmam que fecham a torneira ao escovar os dentes e $100 \%$ praticam o hábito de reutilização da água em suas residências para lavar a casa, porém, também utilizam para lavar calçadas, veículos, roupas, molhar quintal, plantas e hortas. As turmas do período vespertino também responderam estas mesmas perguntas, apresentando o seguinte perfil de resultados: nas turmas do Ensino Fundamental (6ㅇ, 7으, 8으 e 9ㅇ ano), sendo que, respectivamente $87 \%, 50 \%$, $75 \%$ e $90 \%$ disseram que fecham a torneira ao escovar os dentes e maioria $(83 \%, 46 \%, 65 \%$ e $71 \%)$ reutilizam água em suas residências principalmente para lavar a casa e as calçadas, mas também utiliza para lavar veículos, roupas, molhar plantas, horta, quintal e para outras atividades. Já as turmas do Ensino Médio 84\%, 76\% e $89 \%$ respectivamente afirmam que além de fecharem a torneira para escovar os dentes, também reutilizam a água ( $80 \%, 76 \%$ e $39 \%$ ) principalmente para lavar a casa, calçadas e veículos, mas também para lavar roupa, molhar plantas, horta e molhar o quintal.

Confirma Barreto et al. (2008), que por menor que seja a sociedade, é fundamental que a mesma possa ter consciência da questão de utilização consciente da água. Assim também afirma Aoyama et al. (2007), que as menores atitudes de transformações e costumes diário de cada um conseguem, realmente, saber os principais caráteres sustentáveis de um determinado bem significativo assim como a água. Desta forma com a diminuição do uso inconsciente da água, em que resulta em equilíbrio e contribui a continuação das futuras gerações.

Conforme Morelli (2005), o aumento gasto de água apresenta o acontecimento da reutilização articulando alguma precisão inicial. Esse método necessita ser avaliado de alguma forma, do mesmo modo consequente da água, assim como compreende ainda o domínio de prejuízos, diminuindo o gasto de água e a, reduzir a origem de resíduos.

Já para Anschau et al. (2017), além da necessidade de minimizar os gastos atribuídos ao consumo exacerbado da água no planeta, faz-se necessário também, reduzir a devastação das matas localizadas as margens do curso d'água, também denominadas de 'Zonas Ripárias', pois a mesma tem a função primordial de garantir a filtragem de sólidos e de dejetos humanos, assim como de herbicidas, ciclagem de nutrientes e a garantia da permanência da água dentro do ecossistema aquático.

De acordo com a Tabela 3 é possível perceber que mesmo que os alunos deste Colégio apresentem algum conhecimento a respeito da importância de conservação da água como um bem finito, a maioria não repassa este conhecimento adiante (para os pais, familiares e/ou amigos), deixando este conhecimento restrito somente a figura do aluno, quando na verdade, o que se espera é que este conhecimento seja repassado apara além das paredes do muro das Escolas.

Nas turmas do período matutino somente os alunos da 2a Série conversam com seus conhecidos a 
respeito de seus conhecimentos sobre a urgência de se preservar a água para que a mesma não acabe para as futuras gerações, sendo que, todas as turmas do Ensino Fundamental apresentaram resultados inferiores a $50 \%$ no quesito repassar estas informações.

Tabela 3: Expressão da resposta dos alunos quando foram questionados quanto ao repasse de seu conhecimento a respeito dos riscos que envolvem a água, para seus familiares, parentes e/ou amigo.

\begin{tabular}{|c|c|c|c|c|c|c|c|c|c|c|c|c|}
\hline \multirow{3}{*}{ 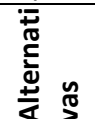 } & \multicolumn{5}{|c|}{ MATUTINO } & \multicolumn{7}{|c|}{ VESPERTINO } \\
\hline & \multicolumn{4}{|c|}{ Fundamental } & \multirow{2}{*}{$\begin{array}{l}\text { Médio } \\
\text { 2a }\end{array}$} & \multicolumn{4}{|c|}{ Fundamental } & \multicolumn{3}{|c|}{ Médio } \\
\hline & 69 & 70 & 80 & 90 & & 60 & 70 & 80 & 90 & $1 \underline{a}$ & 2a & 3a \\
\hline Sim & 33 & 28 & 15 & 44 & 100 & 52 & 54 & 45 & 43 & 35 & 35 & 44 \\
\hline Não & 67 & 72 & 85 & 56 & * & 48 & 46 & 50 & 57 & 70 & 65 & 56 \\
\hline
\end{tabular}

Conforme Tucci (2005), afirma que somente 2,7\% completa de água do mundo é livre e adequada com destino a utilização do ser humano, dessa forma, também através da ausência de domínio a respeito da importância diante do conhecimento, e da quantia de água usada na maior parte dos domicílios, a urgência de impactar a respeito desse amplo valor na rotina de um recurso tão grande valioso com destino ao gênero humano.

Nas turmas do período vespertino esta realidade não mudou, sendo que nenhuma das turmas ultrapassou um percentual acima de $60 \%$ dos alunos que repassem o seu conhecimento sobre a água para os seus conhecidos, sendo que os resultados ficaram entre 35 a $54 \%$ dos alunos que esclarecem a realização desta prática.

O questionário também apresentou aos alunos uma pergunta aberta para saber qual a opinião dos mesmos a respeito do que eles acreditam que irá acontecer com os seres vivos na Terra caso a água do planeta venha sumir totalmente. Sendo que a maioria dos alunos disseram que não existirá vida no planeta caso a água venha a desaparecer. Alguns alunos afirmaram que não sabem o que poderá acontecer e outros não responderam à questão.

\section{CONCLUSÕES}

Em virtude dos fatos mencionados observa-se que os alunos não compreendem que a água não é um bem infinito e que precisa ser conservado nos pequenos hábitos diários, desde fechar a torneira para escovar os dentes até a evitar jogar lixo e dejetos nos corpos hídricos. Desta forma se acredita que a melhor solução seria capacitar todos os professores, que estão envolvidos no desenvolvimento e formação dos discentes, e que esse tema deve ser trabalhado tanto no ensino fundamental Il quanto no médio, não só em uma disciplina mas em todas, de modo a se tornar obrigatória no currículo escolar em Tema Transversal, e realizar campanhas com o auxílio dos alunos, maximizar a quantidade de palestras etc., que seria uma forma de mobilização é o mais convincente e eficaz para a modificação de atitude, pois leva-los a ser um ser pensante capaz de modificar-se pelo conhecimento.

\section{REFERÊNCIAS}

ACSELRAD, H.. O zoneamento ecológico-econômico e a multiplicidade de ordens socioambientais na Amazônia. Novos Cadernos Naea, v.3, n.2, 2008.
ANSCHAU, S. A.; NERES, J. C. I.; CARVALHO, A. V.; GUIMARÃES, A. P. M.; NERES, L. L. G. F.; CERQUEIRA, F. B.. 
Vegetação ripária e métodos de estudo. Natural Resources, v.7, n.1, p.19-32, 2017. DOI: https://doi.org/10.6008/SPC2237-9290.2017.001.0003

AOYAMA, E. S.; SOUZA, I. A. S.; FERRERO, W. B.. Análise de consumo e desperdício de água em atividades diárias por alunos da Unicamp. Revista Ciências do Ambiente, v.3, n.2, 2007.

BARRETO, L. M. P. A.; SILVA, S. A. H.; PÁDUA, S. M.. A contribuição da educação ambiental no processo de gestão ambiental em indústria petroquímica. In: ENCONTRO DA ASSOCIAÇÃO NACIONAL DE PESQUISA E PÓS-GRADUAÇÃO EM AMBIENTE E SOCIEDADE, 4. Anais, 2008.

BARROS, J. B.; FREITAS, K. T. S.; CORREA, I. C.; GUEDES, J. C.; SANTOS, H. O.; OLIVEIRA, J. S.; GUIMARÃES, A. P. M.. Ciência $x$ Religião: a didática utilizada por professores de escolas públicas de Guaraí/TO que ministram a disciplina de Evolução e possuem convicção religiosa. Educationis, v.5, n.2, p.15-23, 2017.

CARVALHO, V. S.. Educação ambiental \& desenvolvimento comunitário. Copacabana: Wak, 2006.

CHAUI, M. S.. Ideologia e educação. Educação e Pesquisa, v.42, n.1, p.245-258, 2016.

DALZOTTO, E.; CARNIATTO, I.. Educação Ambiental: Atividades de percepção e instrução para a preservação de nascentes em áreas degradadas: Um desafio para construção da agenda 21 local. Ponta Grossa, 2009.

DAROLT, M. R.. Lixo rural: do problema a solução. Com Ciência. Revista Eletrônica de Jornalismo Científico, Campinas, v.1, n.95, p.23-26, 2008.

ESTENDER, A. C.; ANDRÉ, D. S.; OLIVEIRA, L.. Conservação e uso racional da água: novos hábitos para evitar a escassez dos recursos hídricos. Revista Brasileira de Administração Científica, v.6, n.1, p.216-229, 2015. DOI: https://doi.org/10.6008/SPC2179-684X.2015.001.0013

GIL, L.. Cortiça: produção, tecnologia e aplicação. Lisboa, 1998.

IBGE. Instituto Brasileiro de Geografia e Estatística. Senso populacional. Rio de janeiro: IBGE, 2016.

IBGE. Instituto Brasileiro de Geografia e Estatística. Departamento de população; indicadores sociais. Pesquisa nacional de saneamento básico: 2000. Rio de Janeiro: IBGE, 2000.

JACOBI, P. R.. Educação ambiental, cidadania e sustentabilidade. Cadernos de pesquisa, n.118, p.189-205, 2003.

KÖPPEN, W. P.. Grundriss der klimakunde. 1931.

LAKATOS, E. M.; MARCONI, M. A.. Técnicas de pesquisa: planejamento e execução de pesquisas, elaboração, análise e interpretação dos dados. São Paulo: Atlas, 1999.

LIMA, N. G.; DORNELAS, K. C. S.; NERES, L. L. F. G.; GUIMARÃES, A. P. M.; NERES, J. C. I.; CARVALHO, A. V.. Analfabetismo ambiental: a percepção dos docentes e discentes sobre o ambiente de uma escola do município de Guaraí/TO. Rev. Ambiente \& Educação, v.23, n.1, p.198-224, 2018.

LIMA, W.. Aprendizagem e classificação social: um desafio aos conceitos. In: FÓRUM CRÍTICO DA EDUCAÇÃO. Anais. 2004. p.29-56.

MACIEL, F. C. A.; SILVA, M. G. O.; CARDOSO, W.; SILVA, M. S.; TAKAHAGASSI, R.; SOARES, A. C.; GUIMARÃES, A. P. M.. O conceito de estruturas celulares na concepção dos alunos do 8o ano de Colmeia/TO. Educationis, v.5, n.2, p.6-14, 2017. DOI: https://doi.org/10.6008/SPC2318-3047.2017.002.0001

MORELLI, E. B.. Reuso de água na lavagem de veículos. Tese (Doutorado) - Universidade de São Paulo, São Paulo, 2005.

LEVY NETO, F.. Estructurais, Compósitos. Ciência e Tecnologia. São Paulo: Edgard Blücher, 2006.

OLIVEIRA, J. A. A.. As contribuições de Paramahansa Yogananda à educação ambiental holística: superando a fragmentação do pensamento do sujeito na ação ambientalista. Dissertação (Mestrado em Educação) Universidade Federal do Ceará, Faculdade de Educação, Fortaleza, 2007.

RAMOS, R. C.; RAMOS, R. C.; SOUZA, V. R.; LOPES, D. D.; MESQUITA, G. V.; GUIMARÃES, A. P. M.. Avaliação do grau de conhecimento de alunos de escolas públicas de dois municípios do interior do estado do Tocantins sobre o conteúdo de Biologia Celular. Educationis, v.5, n.2, p.24-33, 2017.

REIS, E.. Estatística descritiva. 2000.

RICCI, G.. Avaliação da Qualidade da Água de Abastecimento do Município de Porto Velho. Porto Velho: UNIR, 2001.

RICHARDSON, R. J.. Pós-Graduação-Metodologia-Pesquisa Social: Métodos e Técnicas-Métodos Quantitativos e Qualitativos-Capitulo 5. São Paulo: Atlas, 2017.

ROBERTO, M. C.; GUIMARÃES, A. P. M.; RIBEIRO, J. L.; CARVALHO, A. V.; NERES, J. C. I.; CERQUEIRA, F. B.. Avaliação do $\mathrm{pH}$, turbidez e análise microbiológica da água do córrego Guará Velho em Guaraí, Estado do Tocantins. Revista Desafios, v.4, n.4, p.3-14, 2017.

RODRIGUES, C. F. M.; RODRIGUES, V. S.; NERES, J. C. I.; GUIMARÃES, A. P. M.; NERES, L. L. F. G.; CARVALHO, A. V.. Desafios da saúde pública no Brasil: relação entre zoonoses e saneamento. Scire Salutis, v.7, n.1, p.27-37, 2017. DOI: https://doi.org/10.6008/SPC2236-9600.2017.001.0003

SANTOS, E. T. A.. Educação ambiental na escola: conscientização da necessidade de proteção da camada de ozônio. 2007.

SELBORNE, L.. A ética do uso da água doce: um levantamento. 2002.

SEPLAN. Secretaria do Planejamento e da Modernização da Gestão Pública. Base de dados Geográficos: atualização. Palmas: SEPLAN, 2012. 
SILVA, B. B.; ROCHA, L. G.; SILVEIRA, L. P. O.; CARVALHO, A V.; GUIMARÃES, A. P. M.. Análise de qualidade da água do Ribeirão Tranqueira. Revista Ibero-Americana de Ciências Ambientais, v.9, n.8, p.11-25, 2018. DOI: https://doi.org/10.6008/CBPC2179-6858.2018.008.0002

SILVA, S.. Educação ambiental na Escola Municipal Professor Miron, Campina Grande/PB: uma relação escola, sociedade e meio ambiente. 2014.

SILVEIRA, L. P. O.; SOUSA, E. A.; GUIMARÃES, A. P. M.; DOURADO, N. C.. Análise de dados e imagens fotográficas da condição atual de uma área da zona ripária do Rio Tranqueira, no município de Guaraí/TO. Natural Resources, v.7, n.2, p.32-42, 2017. DOI:
http://doi.org/10.6008/SPC2237-9290.2017.002.0004

TUCCI, C. E. M.. Águas urbanas: interfaces no gerenciamento. In: PHILIPPI JR, A.. Saneamento, saúde e ambiente: fundamentos para um desenvolvimento sustentável. Barueri: Manole, 2005.

VICTORINO, C. J. A.. Planeta água morrendo de sede: uma visão analítica na metodologia do uso e abuso dos recursos hídricos. Porto Alegre: Edipucrs, 2007.

VIVEIRO, A. A.. Atividades de campo no ensino das ciências: investigando concepções e práticas de um grupo de professores. 2006.

A CBPC - Companhia Brasileira de Produção Científica (CNPJ: 11.221.422/0001-03) detém os direitos materiais desta publicação. Os direitos referem-se à publicação do trabalho em qualquer parte do mundo, incluindo os direitos às renovações, expansões e disseminações da contribuição, bem como outros direitos subsidiários. Todos os trabalhos publicados eletronicamente poderão posteriormente ser publicados em coletâneas impressas sob coordenação da Sustenere Publishing, da Companhia Brasileira de Produção Científica e seus parceiros autorizados. Os (as) autores (as) preservam os direitos autorais, mas não têm permissão para a publicação da contribuição em outro meio, impresso ou digital, em português ou em tradução. 